\title{
A rotatividade em supermercados na perspectiva dos funcionários
}

\section{Rotativity in supermarkets from the employees' perspective}

\section{RESUMO}

\author{
Sayonara de Fátima Teston ${ }^{1}$ \\ Camila Andressa Krombauer². \\ Carla Fabiana Cazella ${ }^{3}$ \\ Karine Schwaab Brustolim ${ }^{4}$ \\ Daiane Pavan ${ }^{5}$
}

\begin{abstract}
O setor supermercadista demonstra importância para a economia e para o desenvolvimento de diversas regiões brasileiras. Neste contexto, o trabalho tem como objetivo analisar as principais causas da rotatividade em uma rede de supermercados localizado da região Oeste de Santa Catarina no ponto de vista dos funcionários. Os instrumentos para coleta de dados foram primeiramente uma pesquisa documental com as entrevistas de desligamento, seguida por um grupo focal e uma entrevista semiestruturada. A pesquisa documental guiou a elaboração do roteiro para o grupo focal, realizado com funcionários da empresa, bem como, o roteiro da entrevista semiestruturada que foi realizada com a gerente de Recursos Humanos da rede. Para análise dos dados, realizou-se triangulação a partir de categorias préestabelecidas com base na literatura pesquisada e extraídas do campo. Para auxiliar na análise das categorias utilizou-se um software estatístico. Concluiu-se que os motivos principais que contribuem para a rotatividade nesta rede de Supermercados são os aspectos relacionados ao bem-estar no trabalho, justiça e equidade, liderança e relacionamento com colegas de trabalho. A partir das conclusões realizaram-se sugestões de melhoria que são apresentadas no decorrer deste artigo.
\end{abstract}

PALAVRAS-CHAVE: Rotatividade. Gestão de Pessoas. Sociedade pós-moderna. Bemestar.

\section{ABSTRACT}

The supermarket sector shows the importance for the economy and the development of several Brazilian regions. In this context, the objective of this study is to analyze the main causes of turnover in a supermarket chain located in the western area of Santa Catarina from the employees' perspective. The instruments for data collection were primarily a documentary research with shutdown interviews, followed by a focus group and a semi-structured interview. The documentary research guided the focus group script elaboration, carried out with company employees, as well as the semi-structured interview guide conducted with the Human Resources network manager. Data analysis applied consists of triangulation from preestablished categories based on the researched literature and extracted from the field. Statistical software was used to aid analysis. The conclusion points out the main reasons that contribute to the Supermarket's network rotation; those are aspects related to well-being at

\footnotetext{
${ }^{1}$ Doutoranda em Administração, bolsista Capes/CNPq. Professora da Universidade do Oeste de Santa Catarina - Unoesc/Chapecó. E-mail: sayonara.teston@unoesc.edu.br

${ }^{2}$ Graduanda em Administração. Universidade do Oeste de Santa Catarina.

${ }^{3}$ Mestre em Educação, Coordenadora do Curso de Administração da Universidade do Oeste de Santa Catarina.

${ }^{4}$ Mestre em Saúde, Coordenadora do Curso de Psicologia da Universidade do Oeste de Santa Catarina.

${ }^{5}$ Doutoranda em Administração, professora da Universidade do Oeste de Santa Catarina.
} 
work, fairness and equity, leadership, and relationship with co-workers. Based on this, suggestions for improvement are frame during this article.

KEYWORDS: Rotativity. People management. Postmodern society. Well-being.

JEL: A12, M12, R11

\section{INTRODUÇÃO}

O setor supermercadista tem se destacado no cenário nacional. De acordo com a ABRAS (Associação Brasileira de Supermercados), o setor alcançou, em 2015, uma receita bruta de $\mathrm{R} \$ 315,8$ bilhões, o que lhe garantiu participação no PIB brasileiro de $5,35 \%$, o número de funcionários empregados pelo setor passou de 1.836 .789 pessoas em 2014, para 1.847.557 em 2015, bem como, o número de check-outs, de 2014 para 2015 apresentou um crescimento de 1,2\%. Neste contexto, pode-se afirmar que o setor supermercadista tem impacto relevante para as atividades de produção alimentar. Em Santa Catarina, a diversidade de climas, paisagens e relevos estimula o desenvolvimento de inúmeras atividades, e a região Oeste concentra-se principalmente em atividades de produção alimentar. (GOVERNO DO ESTADO DE SANTA CATARINA, 2016). Neste sentido, o setor supermercadista demonstra importância para a economia e para o desenvolvimento regional do oeste.

Apesar do crescimento, no mesmo período em que o mercado de consumo demonstrou crescimento, o setor supermercadista apresentou dificuldades para contratar pessoas (ASSOCIAÇÃO BRASILEIRA DE SUPERMERCADOS, 2015). Desta forma, a rotatividade de funcionários demonstra ser uma problemática para este setor. Conforme os autores Patias e Wittmann (2015), a excessiva rotatividade de pessoal pode causar, além de efeitos intangíveis, a elevação dos custos operacionais. Para auxiliar a minimizar este quadro, é necessário contar com forças internas da organização. Neste contexto, a área de gestão de pessoas de uma organização pode contribuir para um desempenho superior tornando-se fonte de vantagem competitiva sustentável (BRITO; OLIVEIRA, 2016).

Para agregar resultados, este setor precisa alavancar diversas ações relacionadas ao controle da rotatividade. A rotatividade de colaboradores é inevitável para qualquer organização, mas é preciso manter o controle para que não se torne um problema. De acordo com Corrêa et al. (2016) os empresários brasileiros devem ficar atentos à nova realidade do trabalho, encontrando maneiras de manter os trabalhadores ativos já que, como sinaliza a dinâmica populacional brasileira, a oferta de novos trabalhadores não será suficiente para repor pessoas nos postos de trabalho futuramente. Com vistas a esta problemática, o objetivo deste artigo foi analisar as causas principais da rotatividade de uma rede de supermercados da região Oeste de Santa Catarina.

Com o propósito de atender ao objetivo do estudo, será apresentada uma revisão de literatura abordando os principais conceitos da temática e constatações de estudos anteriores. Posteriormente, os procedimentos metodológicos serão descritos, bem como, os procedimentos de coleta e análise dos dados. A seguir, os resultados são discutidos juntamente com as possíveis alternativas para melhoria dos índices de rotatividade e, por fim, as considerações finais do estudo são explanadas. 


\section{A ROTATIVIDADE E O CONTEXTO ATUAL DA GESTÃO DE PESSOAS NA ERA PÓS-MODERNA}

Conceitualmente, a rotatividade explicita o percentual de mudança na composição de todos os funcionários de uma organização em um determinado período (WALDMAN; ARORA, 2004). Segundo o DIEESE (Departamento Intersindical de Estatística e Estudos Socioeconômicos, 2011), a rotatividade representa a substituição do ocupante de um posto de trabalho por outro, ou seja, a demissão seguida da admissão, em um posto específico, individual, ou em diversos postos, envolvendo vários trabalhadores. Marras (2011) também define a rotatividade (ou turnover) como o número de colaboradores desligados da empresa em um determinado período comparativamente ao quadro médio de efetivos.

Neste sentido, a rotatividade faz parte da rotina organizacional. Conforme Triches (2014) em períodos de expansão econômica, quando ocorre o aquecimento do mercado de trabalho, eleva-se o número de desligamentos voluntários em função das chances de mobilidade em direção a empregos com maiores salários, aumentando assim o índice de rotatividade. Na mesma linha de pensamento, Rhoden (2014) afirma que os fatores desencadeadores da rotatividade podem ser causados pela globalização, pois gera competitividade entre as organizações e faz com que aumente a oferta de empregos. Nesta perspectiva, também seria possível afirmar que a situação inversa, de crise econômica, tende a fazer com que as pessoas permaneçam mais tempo em seus empregos. Para Gonzaga e Pinto (2014), os aspectos da legislação trabalhista brasileira, combinados com o baixo cumprimento das leis, geram incentivos à alta rotatividade do trabalho. Entende-se que estes fatores não podem ser descartados como fonte de influência da rotatividade. Porém, além da situação do ambiente externo, outros autores apontam justificativas para elevadas taxas de rotatividade.

Vários autores (CAMPOS; MALIK, 2008; MENEZES; BASTOS, 2010; CAVAZOTTE; OLIVEIRA; MIRANDA, 2010; AGAPITO; POLIZZI FILHO; SIQUEIRA, 2015) demonstraram que há relação positiva entre a intenção de sair da organização e bem-estar no trabalho. Assim, os aspectos relacionais do indivíduo com seu ambiente de trabalho ganham importância. Para Agapito et al. (2015, p. 85) para que a rotatividade permaneça em um nível aceitável, "é essencial que os gestores se preocupem em manter seus colaboradores satisfeitos em relação à chefia, aos colegas, ao trabalho em si, ao salário e às promoções". Para Gonzaga e Pinto (2014), o baixo investimento em capital humano é uma das fontes da rotatividade. Assim, a categoria do bem-estar parece englobar várias outras.

Para Araújo e Cappi (2015), a satisfação no trabalho ocorre à medida que o empregado percebe sua relação com a organização, e quando há sentimento positivo do trabalhador sobre o seu emprego. Parece que o bem-estar no trabalho tende a reduzir os índices de rotatividade. Silva (2013) também enfatiza o papel desempenhado pelos líderes no ambiente de trabalho, tanto no processo de reconhecimento monetário como no reconhecimento da conexão do perfil dos empregados às competências e estratégias da organização. Neste sentido, os líderes parecem ocupar uma posição de destaque na influência para a rotatividade e promoção do bem-estar.

Silva (2013) também chama a atenção para a importância do equilíbrio entre vida pessoal e trabalho, que está relacionado às práticas de flexibilidade no trabalho 
e às políticas e práticas que visam a manutenção do sentimento de justiça e equidade entre os funcionários; o estímulo para a promoção de uma visão sistêmica, por meio de atividades de trabalho em equipe, com desafios e maior significado do seu trabalho para organização e para si mesmo; e, às possibilidades atrativas de carreira na organização. Assim, equilíbrio entre vida pessoal e profissional também aparece como uma categoria que engloba outras diversas.

Diante desta situação complexa e multifacetada, encontra-se a Gestão de Pessoas, que aqui não será definida como um setor, mas como uma responsabilidade, a qual, principalmente os líderes da organização precisam exercer. Assim, conforme afirma Girardi (2008), a era da informação, expôs às organizações o desafio da gestão de pessoas em substituição à gestão de recursos humanos tradicional. As pessoas e a gestão da subjetividade passaram o ocupar um papel central, pois "o ser humano começa a ser percebido como único capital indepreciável, adaptável, auto evolutivo e intransferível, que as organizações podem possuir como diferencial competitivo" (GIRARDI, 2008, p. 63). Sob esta ótica, a concepção de capital humano do século XXI passa a ocupar papel central para as organizações.

Para Davel e Vergara (2008), as pessoas constituem fonte de vantagem competitiva, em virtude de seu valor, potencialidades e qualidades. Por conseguinte, um aspecto crucial da competitividade organizacional está relacionado aos processos de gestão de pessoas no trabalho. Hanashiro et al. (2008), parecem corroborar, afirmando que os talentos são escassos e a principal questão da vantagem competitiva, nos próximos anos, está em saber retê-los. Para que as pessoas permaneçam nas organizações, emerge a necessidade de voltar os olhos para os atores organizacionais e para as necessidades demandadas pelo momento atual. Desta forma, uma das principais preocupações das organizações é manter as pessoas que contribuem para $O$ alcance dos objetivos organizacionais (HAUSKNECHT; RODDA; HOWARD, 2009).

A visão contemporânea da gestão de pessoas, considera que o indivíduo precisa estabelecer um vínculo social com a organização e com a atividade que executa, sendo reconhecido e valorizado como um ser completo. Na contramão, Patino e Arbelaz (2016, p. 102) afirmam que as ciências sociais e gestão "procuram dar respostas aos problemas de produtividade, rentabilidade, otimização e controle". Então, embora tenha havido muitos discursos que consideram o fator humano como ator organizacional, esta concepção continua sendo reducionista quando a subjetividade continua sendo desconsiderada.

Esta perspectiva levanta o retorno às dimensões esquecidas como a "natureza genérica e singular de seres humanos; sua natureza ativa e reflexiva; o uso da palavra, a vida emocional; produção simbólica, a concepção de espaço temporário e alteridade como um processo de construção do indivíduo" (PATINO; ARBELAZ, 2016, p. 103). Esta concepção considera que as pessoas fazem parte da organização e a organização faz parte delas, tornando-as seres ativos, responsáveis pela solução dos problemas, pois apresentam autonomia para aprender e desenvolver-se, e com isso, promover o desenvolvimento da organização, que é parte da sua própria identidade.

Aktouf (2009) sugere a necessidade de compreender que as ferramentas administrativas e sofisticações tecnológicas não são nada se não houver clima social e humano para a adesão, colaboração e desempenho", sugerindo que estas ferramentas existem para servir as pessoas e não para que as pessoas vivam e trabalhem para servir a elas. Sob este ponto de vista, alcança-se o verdadeiro significado da motivação, que é intrínseca. De acordo com Gouvêa et al. (2011), compreender a satisfação e a motivação no trabalho, exige conhecer o que é 
valorizado pelas pessoas integrantes das organizações. Caso a organização consiga alcançar este patamar de aproximação com as necessidades humanas, a gestão torna-se uma via de mão dupla, com ganhos para a organização e para as pessoas que fazem parte dela.

Essa tendência a reconhecer, cada vez mais, a importância do fator humano para o desempenho das organizações exige a adoção de um modelo de gestão de pessoas compatível com o conjunto de transformações em curso nos contextos produtivos (SCHMIDT; KRAWULSKI; MARCONDES, 2013). Em um contexto no qual as pessoas, sua motivação e os resultados no trabalho ocupam papel central para alcançar diferencial competitivo, a rotatividade torna-se um problema de caráter estratégico. Assim, aspectos objetivos e subjetivos relacionados à gestão, encontram espaço de complementaridade.

Nessa conjuntura complexa, a gestão de pessoas parece constituir-se como componente essencial da busca pela satisfação do trabalho. De acordo com Steil et al. (2016), a capacidade para manter profissionais no quadro funcional resulta da estratégia de gestão de pessoas da organização pois ela influencia os processos psicossociais, "incluindo o comportamento de permanecer ou de deixar a organização" (STEIL; PENHA; BONILLA, 2016, p. 99).

Oviedo (2015), fez um resgate sobre os desafios da gestão de pessoas diante das carreiras contemporâneas. Em seu estudo, propõe uma análise histórica das concepções de carreira em dois períodos, sendo o primeiro período de 1900 a 1970. $\mathrm{O}$ autor afirma que durante o primeiro período, estudos de carreira estavam focados nas organizações industriais, caracterizada pela atribuição de tarefas de rotina dentro de uma estrutura hierárquica, e a carreira era entendida como a viagem dos indivíduos dentro da estrutura organizacional em sentido contínuo e ascendente. O segundo período, compreendido como após 1970 até os dias atuais, denominado de pósmoderno, a carreira é vista como uma construção formada nos processos individuaisorganizacionais, por meio da qual geram-se estruturas coletivas e experiências individuais e, a carreira passa a ser um projeto em construção conjunta com o projeto de vida de cada pessoa, sempre em uma dinâmica relacional (OVIEDO, 2015).

Desta forma, a concepção pós-moderna de gestão de pessoas parece exigir novas posturas. O pós-modernismo para Mello (2016, p. 234), "caracteriza-se sobremaneira pela indiferenciação, pela experimentação descompromissada, numa pretensa fuga ao formalismo e ao doutrinário". Talvez as organizações de trabalho estejam atuando de forma contrária e distante da sociedade pós-moderna, e isto esteja se refletindo na rotatividade. Bauman, no início dos anos 2000, já afirmava que "o ambiente social em que as pessoas conduzem os afazeres da vida, mudou radicalmente desde o tempo em que os trabalhadores que se amontoavam em fábricas de produção em larga escala e se uniam para lutar por termos mais compensadores de venda do seu trabalho" (BAUMAN, 2001, p. 209).

Parece que a forma como a gestão é conduzida, precisa estar alinhada com o perfil das pessoas, e com o momento social, pois ambos perpassam o ambiente organizacional. De acordo com Steil et al. (2016), com a diminuição da previsibilidade organizacional e da estabilidade no emprego, situação encontrada com frequência no Brasil, as definições tradicionais de carreira deixaram de explicar a realidade dos profissionais, especialmente dos que ingressaram no mercado de trabalho mais recentemente e/ou que fazem parte de diferentes gerações.

Silva (2013) afirma que é comum encontrar na literatura classificações acerca das gerações das pessoas baseadas em idade. Como consequência, colaboradores pertencentes a diferentes grupos de faixas etárias que atuam em uma mesma 
organização tendem a possuir distintas expectativas, características e diferentes sistemas de valores, o que tende a dificultar o processo de gestão de pessoas. Os períodos utilizados por Parry e Urwin (2011) para caracterizar as gerações são de 1945 a 1967, geração baby boomers; de 1968 a 1979, geração X; e de 1980 a 1991, geração Y. Optou-se por abordar somente estas três gerações no estudo, uma vez que o maior número de funcionários da empresa lócus da pesquisa encontra-se nesta faixa.

Em sua tese doutoral, Silva (2013) elaborou um quadro resumo com as principais características de cada faixa etária acerca dos constructos: comprometimento organizacional, significado do trabalho, responsabilidade social, remuneração, equilíbrio entre vida pessoal e trabalho, aprendizado e desenvolvimento, possibilidades de crescimento profissional, liderança e relacionamento com colegas.

Neste quadro, a geração baby boomers é classificada com tendência a ter maior comprometimento com as organizações, valoriza trabalhos com significado e que criam identidade com a organização, dedica-se mais ao trabalho realizado nas organizações do que a sua vida pessoal, as possibilidades de crescimento de carreira não são suas prioridades, gosta do estilo de gestão participativo, e demonstra habilidades políticas.

A geração $X$, por sua vez, é identificada como aquela que tende a ter baixo comprometimento com as organizações, busca independência em suas atividades e anseia por desafios no trabalho, prefere esquemas mais flexíveis de trabalho a fim de dispor de tempo para se dedicar aos objetivos pessoais. Ela anseia por possibilidades de crescimento na carreira, prefere o relacionamento informal com as lideranças e colegas de trabalho, gosta de trabalhar sozinho.

Já os indivíduos da geração $Y$ tendem a ter baixo comprometimento com as organizações, apreciam a liberdade e a velocidade, anseiam por desafios, preferindo esquemas mais flexíveis a fim de dispor de tempo para se dedicarem aos seus objetivos pessoais, apreciam oportunidades de aprender novas habilidades. Eles anseiam por crescer rapidamente na carreira, esperam que o líder os oriente e que seja uma referência, gostam de compartilhar informações e de estar em contato com as pessoas no ambiente virtual, dentro e fora das organizações. (SILVA, 2013).

Há diferenças e semelhanças significativas entre as gerações e que podem afetar as relações e a decisão pela permanência no trabalho. Para ambas as gerações, Silva (2013) identificou que ações de responsabilidade social corporativa podem atraí-los, há valorização por recompensas e reconhecimento no trabalho, e, todos apreciam oportunidades de aprender novas habilidades.

Ressalta-se que para Veloso (2012) os fatores de relacionamento com as lideranças e colegas de trabalho mostraram maior distinção entre as gerações. Para o autor, enquanto gostam de uma gestão participativa e o relacionamento é visto como meio de atuação política pela geração baby boomers, a geração X prefere uma relação mais informal com as lideranças e um trabalho mais independente da participação dos colegas. E a geração $Y$, por sua vez, espera que o líder seja uma referência para sua carreira, e entende que o relacionamento interpessoal vai além das fronteiras da empresa (VELOSO, 2012). Cada geração possui suas especificidades e, por essa razão, infere-se que a convivência dessas gerações no ambiente organizacional aliada a outros aspectos é o que constitui a cultura, o clima organizacional, o clima psicológico e consequentemente, ocorre a influência na rotatividade organizacional.

\section{PROCEDIMENTOS METODOLÓGICOS}


Trata-se de um estudo por meio do qual foram analisados os motivos principais da rotatividade em uma rede de supermercados do Oeste de Santa Catarina. A rede de supermercados possui um quadro total de 542 colaboradores, distribuídos em quatro supermercados, sendo que os instrumentos para coleta de dados foram pesquisa documental com as entrevistas de desligamento realizadas nos anos de 2013, 2014 e 2015, grupo focal com colaboradores da rede e entrevista semiestruturada com a Gerente de Recursos de Humanos.

As informações coletadas e analisadas nas entrevistas de desligamento guiaram a construção do roteiro do Grupo Focal e a entrevista com a gestora de Recursos Humanos. Para o grupo focal, foram sorteados colaboradores por meio de um relatório emitido pelo sistema de cartão ponto. O grupo focal foi realizado no mês de agosto de 2016, com intuito de colher informações sobre a visão a respeito da rotatividade, sendo que a investigação se aprofundou em itens específicos a partir da fala dos próprios participantes. Os temas do roteiro do grupo focal foram: significados e entendimento da rotatividade; principais motivos que levam as pessoas a sair da empresa; fatores que afetam a satisfação no trabalho; fatores importantes para que as pessoas permaneçam trabalhando na empresa; o que acreditam ser necessário para melhorar o índice de rotatividade. Participaram do grupo focal oito funcionários da rede, que discutiram por 57 minutos aspectos relacionados à rotatividade, após assinar o termo de consentimento livre e esclarecido (TCLE).

A entrevista semiestruturada com a Gerente de Recursos Humanos foi realizada no mês de setembro de 2016, com objetivo de verificar qual a sua visão sobre a rotatividade na rede de supermercados. Os temas do roteiro de entrevista foram: principais causas de rotatividade na rede de supermercados; como é realizada a captação e manutenção de pessoal; quais são as políticas de gestão de pessoas; como é o processo de desligamento de pessoas; qual a percepção sobre o fluxo de pessoas na rede de supermercados; o que precisa ser ajustado para amenizar o fluxo de pessoas na rede de supermercados. Tanto a entrevista com a gerente de recursos humanos quanto o grupo focal foram gravados com o consentimento dos participantes e transcritos na íntegra.

Buscou-se consistência na análise dos resultados por meio de multimétodos de coleta de dados e da combinação deles para a construção de reflexões na discussão dos resultados, que ocorreu por triangulação. Inicialmente, esta etapa baseou-se em categorias previamente elencadas com base na revisão de literatura, que foram revistas e ampliadas após a realização do grupo focal e entrevista. A análise do conteúdo transcrito foi realizada com auxílio do Software Maxqda Plus 12. Após, as informações coletadas por meio da entrevista e do grupo focal foram cotejadas com a revisão teórica, o que caracteriza a triangulação. Por meio das análises realizadas com a triangulação dos dados, buscou-se responder ao objetivo da pesquisa.

\section{ANÁLISE E DISCUSSÃO DOS RESULTADOS}

Para nortear o processo de análise e discussão dos resultados, realizou-se uma categorização dos principais motivos de desligamento de acordo com as informações levantadas na literatura, sendo: ambiente externo, legislação trabalhista, falta de investimento no capital humano, bem-estar no trabalho, liderança, relacionamento com colegas, salário, justiça e equidade, oportunidades de crescimento na carreira, equilíbrio entre vida pessoal e profissional. Além das categorias pinçadas da revisão 
teórica, emergiram mais três categorias do campo: preconceito, comunicação, condições de infraestrutura. Apesar de alguns autores da revisão de literatura incluírem subcategorias em alguns itens citados, para fins operacionais da pesquisa, optou-se por elencar sistemas de códigos individuais, que podem ser verificadas na Figura 1.

Figura 1 - Matriz de códigos

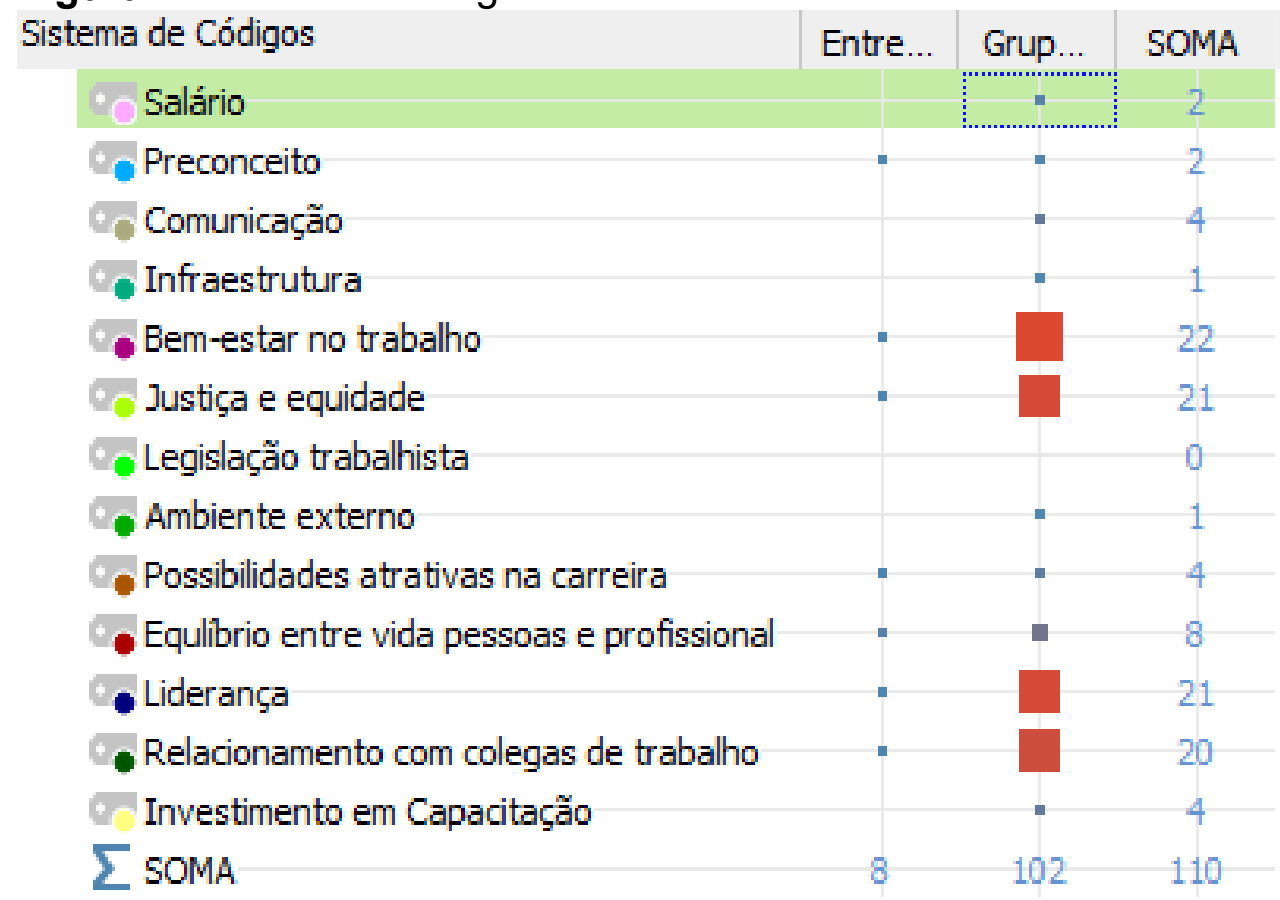

Fonte: Elaborado pelas autoras com base nos dados da pesquisa, 2016.

De acordo com a figura, pode-se verificar que os itens que demonstraram maior frequência foram bem-estar no trabalho, liderança, relacionamento com colegas, justiça e equidade. Todos os construtos apresentaram relação com bem-estar no trabalho, conforme pode ser verificado na Figura 2.

Figura 2 - Modelo de co-ocorrência de códigos 


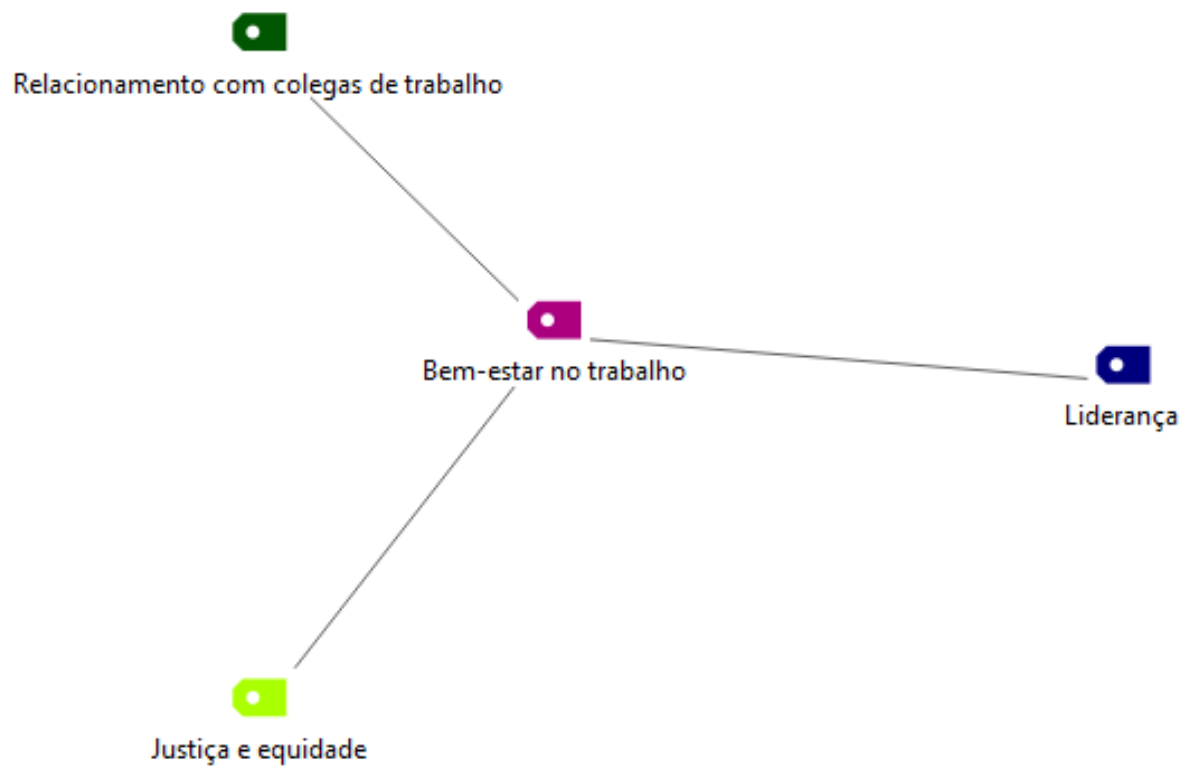

Fonte: Elaborado pelas autoras com base nos dados da pesquisa, 2016.

As quatro categorias guiaram a análise do estudo e as sugestões de melhoria para a rede. A escolha destas quatro categorias justifica-se por serem os temas que surgiram com mais frequência nos grupos focais e na entrevista com a Gestora de Recursos Humanos. As categorias serão discutidas separadamente.

\section{Relacionamento com colegas de trabalho}

Para que a rotatividade permaneça em um nível aceitável, é importante que os gestores se preocupem em manter seus colaboradores satisfeitos em relação aos colegas, juntamente com diversos outros fatores relacionados ao bem-estar (AGAPITO; POLIZZI FILHO; SIQUEIRA, 2015). Sobre este constructo, os participantes do grupo focal demonstraram verbalizaram:

Tem bastante gente que ta saindo por causa do coleguismo, [...] por que faz dois anos que to trabalhando no setor e eu entrei agora, aí ensinei, ensinei uma, ensinei duas, depois da terceira não ensino mais ninguém. Se tu pegou, pegou, não pegou não to nem aí.

Parece que os índices elevados de rotatividade fazem com que os funcionários que decidem permanecer também sejam afetados, pois há dificuldade em manter 0 conhecimento na empresa e o vínculo com os colegas. Na entrevista, a gestora de Recursos Humanos demonstrou que conhece os problemas por outros instrumentos de pesquisa aplicados anteriormente, e entende que a maior frequência de problemas de relacionamento ocorre entre as pessoas com mais tempo de empresa. Infere-se, que para pessoas que tenham a característica de firmar vínculos mais estáveis com a empresa, e consequentemente com os colegas, seja mais difícil de vivenciar saídas e entradas constantes de pessoas na organização, fazendo com que contribuam para que o processo de adaptação de novos contratados seja dificultado. Tirar os funcionários mais antigos talvez agrave a situação, pois são eles quem detêm maior 
conhecimento acerca dos processos operacionais. Envolvê-los na solução deste desafio talvez seja a saída mais adequada.

Veloso (2012) menciona que, ao lado do relacionamento com líderes, os fatores de relacionamento com colegas de trabalho mostram maior distinção entre as gerações. Para o autor, enquanto gostam de uma gestão participativa e o relacionamento com colegas é visto como meio de atuação política pela geração baby boomers, a geração $X$ prefere uma relação mais informal com as lideranças e um trabalho mais independente da participação dos colegas. $\mathrm{E}$ a geração $\mathrm{Y}$, por sua vez, espera que o líder seja uma referência para sua carreira, e entende que o relacionamento interpessoal vai além das fronteiras da empresa (VELOSO, 2012). Cada geração possui suas especificidades e, por essa razão, infere-se que a convivência dessas gerações no ambiente organizacional aliada a outros aspectos, neste caso, com o bem-estar, constitui o clima organizacional e o clima psicológico, o que ressoa na rotatividade organizacional.

Propiciar para que haja compreensão acerca do funcionamento das gerações pode contribuir para que possíveis alternativas de atuação sejam criadas pelos envolvidos. Sugere-se também que algumas situações relacionadas aos vínculos entre colegas sejam monitoradas pelos gestores de pessoas, bem como, indica-se uma preparação dos líderes para que consigam agir de forma pontual e próxima dos funcionários em situações que envolvam relacionamento interpessoais entre os colegas. Entre diversas ações possíveis, esta intervenção pode iniciar com treinamentos de trabalho em equipe para os cargos operacionais, e de mediação para os líderes, já que, na opinião da Gestora de RH os treinamentos são bem aceitos e são eficazes, e na opinião dos funcionários que fizeram parte do grupo focal, poderiam ser realizados mais capacitações, direcionadas principalmente para relações interpessoais.

\section{LIDERANÇA}

Os líderes ocupam uma posição de destaque na influência para a rotatividade e promoção do bem-estar, conforme pode ser verificado na fala do grupo focal:

Tem líder que você fica dois, três dias sem ver ele no setor, então assim, isso vai gerando também uma falta de apoio, você olha pro lado não tem com quem falar você tem um problema teu líder geralmente não ta ali.

Silva (2013) enfatiza o papel desempenhado pelos líderes no ambiente de trabalho, tanto no processo de reconhecimento monetário quanto no não monetário. Percebe-se que os funcionários entendem que o papel dos líderes vai além de apresentar resultados operacionais, esperando receber apoio e proteção acerca de questões emocionais e afetivas. Conforme afirma Aktouf (2009), a necessidade de compreender as ferramentas administrativas e sofisticações tecnológicas não são nada se não houver clima social e humano para a adesão, colaboração e desempenho.

A aproximação afetiva faz parte do papel do gestor de pessoas contemporâneo e ele precisa estar preparado para responder a esta necessidade. Algumas verbalizações demonstrando certo distanciamento foram mencionadas no grupo focal:

Nossa! Parece que estão distantes das outras por que eu vejo as líderes principalmente de frente de caixa, é assim né, sinal de olhar por cima, orgulhosas, nariz empinado. 
A diferenciação entre cargos é típica de organizações hierárquicas, porém, parece que os funcionários estão relatando como se sentem em relação aos líderes, ocupando um lugar de inferioridade, pois eles teriam que "olhar para baixo" para vêlos, o que pode gerar sentimentos negativos em relação ao ambiente. Araújo e Cappi (2015), afirmam que a satisfação no trabalho ocorre à medida que o empregado percebe sua relação com a organização, e quando há sentimento positivo do trabalhador sobre o seu emprego. Sugere-se que o bem-estar no trabalho tende a reduzir os índices de rotatividade, porém, quando o funcionário prefere ficar distante do líder de setor, surge a demonstração que o vínculo e a confiança no trabalho do outro pode estar prejudicada:

Às vezes, quando o chefe não tá, é uma paz danada.

Quando a figura do líder está relacionada a alguém que dificulta o andamento natural do trabalho, pode estar havendo uma falta de promoção da visão do todo para os funcionários, bem como, uma falta de envolvimento deles para que possam melhorar os processos e compreender que as funções precisam se complementar, e não gerar resultados opostos. Promover esta melhoria necessita de envolvimento e condução por parte dos líderes. A Gerente de Recursos Humanos da empresa, afirma que a liderança tem total influência para a rotatividade dos colaboradores já que o colaborador tem contato frequente com o líder, e o mesmo influencia o andamento de todas as atividades que ocorrem na rede de supermercados, afirmando que:

O líder tem total influencia, as pessoas se desligam do líder.

Deixar a responsabilidade pela rotatividade somente para os líderes é arriscado, uma vez que a liderança e sua forma de atuação é influenciada pela cultura organizacional como um todo. Portanto, trabalhar a rotatividade é um processo, e não um evento, exigindo ações de curto, médio e longo prazos.

Notou-se também nas verbalizações do grupo focal que os colaboradores não têm uma comunicação eficaz com a liderança ou com o setor de recursos humanos sobre as dificuldades. Os colaboradores citaram a falta de segurança para conversar com o setor de RH por medo de que as informações sejam espalhadas e aconteça algum tipo de perseguição durante o trabalho. Assim, infere-se que a relação com os líderes ou com o próprio setor de $\mathrm{RH}$ parece estar sofrendo com a forma como o fluxo das informações é realizado na empresa, bem como, pela forma como é dado encaminhamento aos problemas. Sugere-se uma revisão do processo de comunicação com vistas para a imparcialidade. Além disso, sugere-se capacitação para os líderes com foco em gestão de pessoas, comunicação e feedback, e para os funcionários com foco em relações humanas, comunicação e feedback. Propõem-se também a realização de uma pesquisa de diagnóstico organizacional, apresentação dos resultados e da visão da empresa para o futuro, o que certamente exigirá ajustes sobre os índices de rotatividade para que o desenvolvimento da empresa seja sustentável.

\section{Justiça e equidade}

Os aspectos relacionados à categoria da justiça e equidade é complexa pela multiplicidade de fatores envolvidos. Entre os fatores, surgiu discussão acerca das 
dificuldades com o cronograma de folgas; da responsabilidade com as tarefas e salário recebido; das dúvidas quanto aos descontos da folha de pagamento; e, do tratamento do líder com a equipe quando surgem dificuldades operacionais. Fica evidente nas falas recortadas do grupo focal a afirmação de Silva (2013), que chama a atenção para a importância do equilíbrio entre vida pessoal e trabalho, já que este constructo está relacionado às práticas de flexibilidade no trabalho e às políticas e práticas que visam a manutenção do sentimento de justiça e equidade entre os funcionários.

A Gerente entrevistada acredita que o principal aspecto relacionado ao sentimento de justiça e equidade que interfere na rotatividade é o trabalho em finais de semana e feriados, dificultando a convivência social e familiar. Este foi o primeiro aspecto levantado no grupo focal após a provocação das mediadoras acerca dos motivos principais que levam as pessoas a deixar a empresa, o que indica que este é um aspecto bastante significativo para os funcionários:

Eu trabalhava dois dias e folgava dois e, agora eu trabalho dois e folgo um, e nunca bate com a folga da esposa. Dá uma diferença na vida da gente.

O grupo focal levantou a discussão acerca da remuneração e das diferenças existentes entre os cargos. A Gerente de Recursos Humanos acredita que o salário não é um fator de influência para os desligamentos, já que a remuneração é compatível com o mercado de trabalho do Oeste Catarinense. É importante ressaltar que a queixa apresentada pelo grupo não foi sobre o valor do salário, mas sim, sobre o sentimento de injustiça e falta de equidade da remuneração que recebem em relação aos colegas que executam tarefas diferentes:

A responsabilidade que nós temos, a maioria das vezes temos que passar, empacotar, atender, observar se o produto não passou, se não foi registrado duas vezes, e os empacotadores ganhando o mesmo salário que nós com a diferença do quebra, isso as vezes dá uma desanimada, isso dá uma entristecida.

No grupo focal, surgiram também apontamentos acerca de dúvidas com a relação entre o salário recebido e as horas trabalhadas. A Gerente de RH explicou que a empresa trabalha com banco de horas, porém, algumas funções consideradas estratégicas, recebem em folha de pagamento o valor das horas extras para que se ausentem o mínimo possível da empresa para folgar. Esta postura adotada pela organização, gera dúvidas por parte dos funcionários, já que eles comparam o salário final recebido entre eles e mencionam:

Se tu trabalha oito horas por dia você tinha que receber a oito horas.

Percebeu-se também que o aspecto da liderança perpassa o sentimento de justiça e equidade levantados pelo grupo focal. Retoma-se a importância do comportamento do líder, o que também foi ressaltado pela Gerente de Recursos Humanos, no sentido da imparcialidade com relação à equipe de trabalho, e desenvolvimento de habilidades de realização de feedbacks:

Passam a mão na cabeça de fulano, o problema ta nele aí, em você não, mas não vou chamar ele, vou me sentir mal, aquela saia justa, então vou chamar todo mundo e vou falar ou xingar com todo mundo. 
Como sugestões, indica-se uma reorganização da escala de folgas, aponta-se para a possibilidade de ampliar contratações para membros do mesmo núcleo familiar para setores diferentes, o que, hipoteticamente, facilitaria a organização da escala de folgas de familiares para os mesmos dias da semana. Sugere-se que ocorram esclarecimentos acerca da folha de pagamento para os funcionários, e uma revisão do plano de cargos, com atualização da descrição de tarefas e posterior avaliação da remuneração por cargo. Assinala-se também para a adoção de uma política igualitária, acerca da decisão sobre folgas ou pagamento das horas extras. Além disso, recomenda-se um programa de coaching para os líderes, voltado para o desenvolvimento da habilidade de dar e receber feedback.

\section{Bem-estar no trabalho}

Vários autores concordam que um aspecto crucial da competitividade organizacional está relacionado aos processos de gestão de pessoas no trabalho. Davel e Vergara (2008), mencionam o valor, potencialidades e qualidades das pessoas para as organizações; Hanashiro et al (2008) e Hausknecht et al (2009) chamam atenção para a importância da retenção de talentos. Portanto, para que as pessoas permaneçam nas organizações, emerge a necessidade de voltar os olhos para os atores organizacionais e para as necessidades demandadas pelo momento atual. Uma das formas de alcançar este objetivo, é investir em aspectos relacionados ao bem-estar no trabalho, mencionados em diversos momentos no grupo focal:

A gente busca um ambiente bom de trabalho, que você venha aqui e não seja aquela coisa maçante entende, mas que você venha aqui e saia, nossa, hoje foi show!

Ficam evidentes os constructos que apresentaram relação com bem-estar no trabalho, neste caso expresso pela importância dada ao clima organizacional. Diversos fatores constituem o clima organizacional, e também exigem o envolvimento de todos na organização para que seja predominantemente positivo. E, a questão dos vínculos afetivos, novamente veio à tona:

Hoje eu confesso pra vocês, e tenho plena consciência que eu sou aqui um número, na empresa onde eu trabalhei por 20 anos, [...] o Presidente sabia meu nome e aqui, as pessoas dos setores não dizem bom dia.

Desta forma, a concepção pós-moderna de gestão de pessoas parece exigir novas posturas, "numa pretensa fuga ao formalismo e ao doutrinário" (MELLO, 2016, p. 234). Esta fuga do sentencioso exige aproximação em tempos de redes sociais informatizadas, e um olhar voltado ao subjetivismo. Reafirma-se que talvez as organizações de trabalho estejam atuando de forma contrária e distante dos ditames da sociedade pós-moderna, e isto esteja se refletindo na rotatividade.

A Gerente de Recursos Humanos apontou diversos aspectos positivos que podem estar relacionados ao bem-estar no trabalho e que estão acontecendo atualmente na empresa: treinamentos, um processo de seleção estruturado, salário compatível com o mercado de trabalho, entre outras atividades. Porém, os participantes do grupo focal não demonstraram reconhecimento significativo por estes aspectos. Talvez, já façam parte da rotina organizacional e os fatores considerados estressantes podem estar sendo mais significativos do que os fatores de satisfação, fazendo com que a sensação de bem-estar fique abalada e incite a rotatividade. 
Oferecer um ambiente de trabalho favorável à promoção do bem-estar no qual geram-se estruturas coletivas e individuais, onde a carreira passe a ser um projeto em construção conjunta com o projeto de vida de cada pessoa (OVIEDO, 2015), faz parte do discurso acerca na forma contemporânea de gestão de pessoas. Alcançar este patamar, ainda é um desafio não só para esta, mas para muitas organizações.

\section{CONSIDERAÇÕES FINAIS}

Neste estudo procurou-se analisar as principais causas da rotatividade de uma rede de supermercados da região Oeste de Santa Catarina, no ponto de vida dos funcionários. A partir de diversos aspectos levantados da revisão teórica e no campo de estudos durante a coleta de dados, os aspectos que demonstraram ser mais significativos na empresa lócus do estudo foram: bem-estar no trabalho, liderança, relacionamento com colegas, justiça e equidade. $E$ todos os construtos apresentaram relação com bem-estar no trabalho.

A gestão de pessoas vem passando por um contínuo processo de transformação, para a qual estão sendo incorporadas novas práticas de concepção e de atuação. Dentre os desafios que a gestão de pessoas enfrenta, a rotatividade traz à tona a importância de preservar, envolver e desenvolver as pessoas que fazem parte do contexto organizacional. Tendo como pretexto inicial a busca pela vantagem competitiva, na sociedade pós-moderna, evoluiu-se para uma atuação mais abrangente, que visa a cooperação e a troca entre as pessoas e as organizações para o alcance dos objetivos tanto organizacionais quanto individuais do trabalhador. Portanto, para mantê-los motivados, uma série de novas práticas, embasadas por uma nova concepção acerca dos significados do trabalho precisa ser firmada.

Os resultados deste estudo se aplicam somente para a rede de supermercados estudada na região Oeste de Santa Catarina, não podendo ser aplicados para outro supermercado, pois vários aspectos surgiram do campo e guiaram a pesquisa. Uma das limitações da pesquisa foi a restrição por parte da empresa para a divulgação dos aspectos levantados nas entrevistas de desligamento. Assim, sugere-se para pesquisas futuras um estudo voltado para o bem-estar no trabalho nesta rede de supermercados, uma vez que os quatro fatores chave que emergiram do estudo sugeriram aproximação com este aspecto.

\section{AGRADECIMENTO}

Agradecimento à Capes/CNPq pelo auxílio financeiro para bolsa de pesquisa de doutorado.

\section{REFERÊNCIAS}

ABRAS. Associação Brasileira de Supermercados. 2015. Pausa para recuperar o fôlego? Disponível em: http://www.abrasnet.com.br/economia-e-pesquisa/rankingabras/os-numeros-do-setorl. Acesso em: 27 nov. 2016.

AGAPITO, P. R.; POLIZZI FILHO, A.; SIQUEIRA, M. M. M. Bem-estar no Trabalho e Percepção de Sucesso na Carreira como antecedentes da Intenção de Rotatividade. 
Revista de Administração Mackenzie, v. 16, n. 6, p. 71-93, 2015. Doi: http://dx.doi.org/10.1590/1678-69712015/administracao.v16n6p71-93.

AKTOUF, O. La administración: Entre tradición y renovación. Cali: Artes Gráficas del Valle, 2009. Disponível em: https://pt.scribd.com/doc/276211259/20-Aktouf-OmarLa-Administracion-entre-tradicion-y-Renovacion-pdf. Acesso em: 24 nov. 2016.

ARAÚJO, B. F. V. B.; CAPPI, M. N.; Satisfação no trabalho, comprometimento organizacional e intenção de sair: um estudo entre as gerações Xe Y. REAd - Revista Eletrônica de Administração, v. 21, n. 3, p. 576-600, 2015. Doi: http://dx.doi.org/10.1590/1413-2311.0782014.54843.

BAUMAN, Z. Sociedade Líquida. Rio de Janeiro: Zahar, 2001.

CAMPOS, C. V. A.; MALIK, A. M. Satisfação no trabalho e rotatividade dos médicos do programa de saúde da família. Revista de Administração Pública, v. 42, n. 2, p. 347-368, 2008.

CAVAZOTTE, F. S. C. N.; OLIVEIRA,, L. B.; MIRANDA, L. C. Desigualdade de gênero no trabalho: reflexos nas atitudes das mulheres e em sua intenção de deixar a empresa. Revista de Administração, v. 45, n. 1, p. 70-83, 2010.

CORREAA, D. A.; GONÇALVES, W. A.; SANTOS, A. L. L. D.; NETTO, A. F. N. Impactos do Bônus Demográfico para Gestão de Pessoas. Revista de Administração FACES Journal, v. 15, n. 3, p. 69-87, 2016.

DAVEL, E.; VERGARA, S. C. Gestão com Pessoas e Subjetividade. São Paulo: Editora Atlas, 2008.

DIEESE. Departamento Intersindical de Estatística e Estudos Socioeconômicos. Rotatividade e flexibilidade no mercado de trabalho. São Paulo, 2011.

GIRARDI, D. Da seção de pessoal à gestão estratégica de pessoas: consultoria interna de recursos humanos. Florianópolis: Pandion, 2008.

GONZAGA, G.; PINTO, R. C.; Rotatividade do trabalho e incentivos da legislação trabalhista. In: BONELLI, R.; VELOSO, F. (Orgs.). Panorama do Mercado de Trabalho no Brasil. Rio de Janeiro: Editora FGV, 2014.

GOVERNO DO ESTADO DE SANTA CATARINA. Economia de Santa Catarina é rica e diversificada, 2016. Disponível em: http://www.sc.gov.br/economia. Acesso em 27 nov. 2016.

GOUVEAA, M. A.; KUBO, S. H.; MANTOVANI, D. M. N. Significado do trabalho nos setores público e privado. Revista de Ciências Humanas, Florianópolis, v.45, n.2, p.305-330, 2011.

HANASHIRO, D. M. M.; TEIXEIRA, M. L. M.; ZACCARELLI, L. M. Gestão do fator humano: uma visão baseada em stakeholders. 2. Ed. São Paulo: Saraiva, 2008. 
HAUSKNECHT, J. P.; RODDA, J.; HOWARD, M. J. Targeted employee retention: Performance based and job-related differences in reported reasons for staying. Human Resource Management, v. 48, n.2, p. 269- 288, 2009. Doi: 10.1002/hrm.20279.

MARRAS, J. P. Administração de Recursos Humanos: do Operacional ao estratégico. 14 ed. São Paulo: Saraiva, 2011.

MELLO, G. M. C. Pós-Modernismo: entre a Crítica e a Ideologia. Revista Trans/Form/Ação, v.39, n. 1, p. 233-258, 2016. Doi: 10.1590/S0101317320160001000011.

OVIEDO, C. F. T. Gestión de Carreras Contemporáneas: desafíos críticos para la gestión humana. Apuntes del Cenes, v. 34, n. 59, p. 207-220, 2015. Disponível em: http://www.scielo.org.co/pdf/cenes/v34n59/v34n59a09.pdf. Acesso em: 25 nov. 2016.

PARRY, E.; URWIN, P. Generational Differences in Work Values: A Review of Theory and Evidence, International Journal of Management Reviews, v. 13, p. 79-96, 2011. Doi: 10.1111/j.1468-2370.2010.00285.x

PATINO, J. D. P.; ARBELAZ, I. C. L. Gestión Humana de Orientación Analítica: Un Camino para la Responsabilización. Revista de Administração de Empresas, v. 56, n. 1, p. $101-113,2016$. Doi: http://dx.doi.org/10.1590/S0034-759020160109

RHODEN, D. O. Estar e Permanecer: Problemática do absenteísmo e da rotatividade em uma unidade de tratamento de Sementes de Primavera do Leste - MT. 2013. 150 f. Dissertação (Mestrado em Engenharia de Produção), Universidade Federal do Rio Grande do Sul, Porto Alegre.

SCHMIDT, B.; KRAWULSKI, E.; MARCONDES, R. C. Psicologia e Gestão de Pessoas em Organizações de Trabalho: investigando a perspectiva estratégica de atuação. Revista de Ciências Humanas, v. 47, n. 2, p. 344-361, 2013.

SILVA, R. C. A abordagem geracional como proposta à gestão de pessoas. 2013. 178 f. Tese (Doutorado em Ciências), Departamento de Administração, Faculdade de Economia, Administração e Contabilidade, Universidade de São Paulo, São Paulo. Doi: 10.11606/T.12.2013.tde-22012014-140459.

STEIL, A. V.; PENHA, M. M.; BONILLA, M. A. M. Antecedentes da retenção de pessoas em organizações: Uma revisão de literatura. Revista Psicologia: Organizações e Trabalho, v. 16, n. 1, p. 88-102, 2016. Doi: 10.17652/rpot/2016.1.542.

TRICHES, D. Taxa de rotatividade e a nova regra para o aviso prévio: Impactos no mercado de trabalho formal de Caxias do Sul - RS. Revista Economia e Região, v. 2, n. 1, p. 146-164, 2014. Doi: 10.5433/2317-627X.2014v2n1p146.

VELOSO, E. F. R. É possível negar a existência da geração Y no Brasil? Revista Organizações \& Sociedade, v.19, n.62, p. 745-747, 2012. Doi: http://dx.doi.org/10.1590/S1984-92302012000400011. 
WALDMAN, J. D.; ARORA, S. Measuring retention rather than turnover: A different and complementary HR calculus. Human Resource Planning, v. 27, n. 3, p. 1-9, 2004.

Disponível

em:

http://connection.ebscohost.com/c/articles/14659748/measuring-retention-ratherthan-turnover-different-complementary-hr-calculus. Acesso em: 24 nov. 2016. 